\title{
MIGRAINE PROPHYLAXIS WITH DIVALPROEX
}

The effectiveness and safety of divalproex sodium administered daily in migraine prophylaxis were evaluated in 23 children, ages 7 to 17 years (mean, $12.4 \mathrm{yrs})$, at Ohio State University College of Medicine, Children's Hospital, Columbus, OH. Dosage ranged from $250-1125 \mathrm{mg} /$ day $(3.1$ to $32.9 \mathrm{mg} / \mathrm{kg} / \mathrm{day}$ ). Valproate serum levels varied from 18 to $82.3 \mathrm{mcg} / \mathrm{ml}$. Comorbid psychiatric disorders occurred in 7 patients ( 2 with bipolar disorder, 1 with depression, 2 with ADHD, 1 with ADD, and 1 with ODD). Six patients had epilepsy, and seizures were well controlled by divalproex. A greater than $50 \%$ reduction in migraine attacks was obtained in $15(65 \%)$ patients, and 6 of these were headache free. A significant response occurred in patients with migraine alone or comorbid epilepsy. In those with comorbid psychiatric and behavior disorders headaches were not improved. Patients with comorbid epilepsy tended to require higher doses of divalproex $(13 \mathrm{mg} / \mathrm{kg} /$ day) than those with psychiatric disorders (11 $\mathrm{mg} / \mathrm{kg} /$ day) or those with migraine alone $(8.5 \mathrm{mg} / \mathrm{kg} /$ day $)$. The average daily dose for children who responded $(11.6 \mathrm{mg} / \mathrm{kg} /$ day $)$ was not significantly different from that taken by nonresponders $(11.9 \mathrm{mg} / \mathrm{kg} /$ day $)$. Side effects requiring withdrawal of divalproex occurred in 4 patients and included weight gain, lethargy, anorexia, and alopecia. None had significant hematological or hepatic dysfunction requiring drug termination. (Pakalnis A, Greenberg G, Drake ME Jr, Paolicchi J. Pediatric migraine prophylaxis with divalproex. I Child Neurol Oct 2001;16:731-734). (Respond: Dr Ann Pakalnis, Section of Neurology, Children's Hospital, 700 Children's Drive, Columbus, OH 43205).

COMMENT. Divalproex is effective in migraine prophylaxis in children with headache alone or with comorbid epilepsy. Migraine in children with comorbid behavioral disorders does nor respond to divalproex. Previous double-blind, placebo-controlled studies have confirmed the efficacy of divalproex sodium in treatment of migraine, as reviewed by Siberstein SD (Headache 1996;36:547-555), but valproate is generally not recommended for migraine prevention in children under 10 years of age (see Progress in Pediatric Neurology III, PNB Publ, 1997;pp190-191).

\section{SEIZURE DISORDERS}

\section{VALPROATE/LAMOTRIGINE AND GROWTH RETARDATION}

Growth and bone metabolism were evaluated in 27 boys and 26 girls, aged 3 to 17 years (mean $9.2 \mathrm{yrs}$ ), with epilepsy treated with valproate (VPA) and/or lamotrigine (LTG) for $>2$ years, in a study at McMaster University and Children's Hospital, Hamilton, Ontario, Canada. Height was below the 10th percentile in 23 (43.4\%) of the patients, and bone mineral density (BMD) was reduced in 24\%. When patients were divided according to daily activity, the inactive group had significantly lower scores for height percentile, BMD, and biochemical indices for bone metabolism, when compared with the active group. The score for total body BMD was correlated with the daily activity score. Height percentiles were significantly lower in children treated with VPA/LTG combination therapy compared to VPA-alone or LTG-alone. (Guo C-Y, Ronen GM, Atkinson SA. Longterm valproate and lamotrigine treatment may be a marker for reduced growth and bone mass in children with epilepsy. Epilepsia Sept 2001;42:141-1147). (Reprints: Dr Stephanie Atkinson, Department of Pediatrics, McMaster University Medical Center HSC-3V42, 1200 Main Street West, Hamilton, Ontario, L8N 3Z5, Canada). 
COMMENT. Long-term VPA and LTG therapy, especially in combination, is associated with short stature, low bone mineral density, and reduced bone formation. These effects on growth and bone metabolism are correlated with reduced physical activity. Although a specific effect of the anticonvulsant medication on growth and bone mass is unproven, further studies are indicated.

\section{CELIAC DISEASE AND LOCALIZATION-RELATED EPILEPSIES}

The incidence of silent ceilac disease (CD) in children with idiopathic localization epilepsies and the indications for routine $C D$ screening were determined in a study of 72 patients ( 31 girls and 41 boys; mean age 12.6 years; age at onset 6.4 years) observed over a 5 year period at the Institute of Neurology and Gastroenterology, University Magna Graecia of Catanzaro, Italy. The enzymelinked immunosorbent assay (ELISA) for antigliadin antibodies (AGA) and the immunofluorescent undirected test for antiendomysium antibodies (AEA) were used to confirm a diagnosis of CD. ELISA has $>96 \%$ sensitivity and $97 \%$ specificity for IgA-AGA and IgG-AGA antibodies. AEA is a more specific but less sensitive test than AGA. Twenty five patients had childhood partial epilepsy with occipital

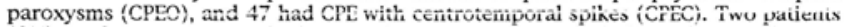
(8\%) in the CPEO group had antiendomysium immunoglobulin (Ig) A antibodies, and their jejunal biopsies showed atrophy of the villi and hyperplasia of crypts, confirming the diagnosis of CD. Brain CT was normal in one and showed occipital cortical-subcortical calcifications in the other. Treatment with a gluten-free diet was followed by seizure remission, and no calcifications developed in the patient with a normal CT after 3 year follow up. None of the patients with CPEC had positive antibody tests for CD. (Labate A, Gambardella A, Messina D et al. Silent celiac disease in patients with childhood localization-related epilepsies. Epilepsia Sept 2001;42:1153-1155). (Reprints: Dr A Gambardella, Cattedra ed UO di Neurologia, Universita degli studi Magna Graecia, Policlinico Mater Domini, Via Tommaso Campanella, 88100 Catanzaro, Italy).

COMMENT. Celiac disease screening is recommended in patients with childhood partial epilepsy with occipital paroxysms (CPEO). Early diagnosis of CD and dietary intervention may reverse the tendency to seizures and the development of brain calcifications. Routine screening for $\mathrm{CD}$ is not indicated in patients with infantile extraoccipital seizures. A new diagnostic test for CD using human recombinant tissue transglutaminase (TACA) may he mere sencitive in the diagnosis of silent forms of CD (Sblattero D et al. Am / Gastroenterol 2000;95:1253-7, cited by the authors).

\section{BENIGN OCCIPITAL SEIZURE SUSCEPTIBILITY SYNDROME}

Thirty seven chidren who met the diagnostic criteria for early-onset benign occipital seizure susceptibility syndrome (BOSSS) were followed prospectively for more than two years at the Tokyo Women's Medical University and Doaikai Hospital, Tokyo, Japan. This diagnosis accounted for $11.7 \%$ of children with localization-related epilepsy, who developed a first seizure before 13 years of age, and presented at one of two seizure clinics between 1989 and 1998. Diagnostic criteria employed were as follows: 1) normal development before seizure onset; 2) onset 1 to 8 years of age; 3) normal MRI or CT; 4) ictal vomiting and tonic eyedeviations; 5) normal EEG background activity with or without epileptic foci regardless of location. The Panayiotopoulos criterion of occipital EEG paroxysms was excluded, since EEG foci often shift to centrotemporal or frontal regions (Ferrie et al 1997; Oguni et al 1999). In this series initial EEG spike foci were occipital in 26 (70\%), 17 of whom later revealed a shift in location, extraoccipital 